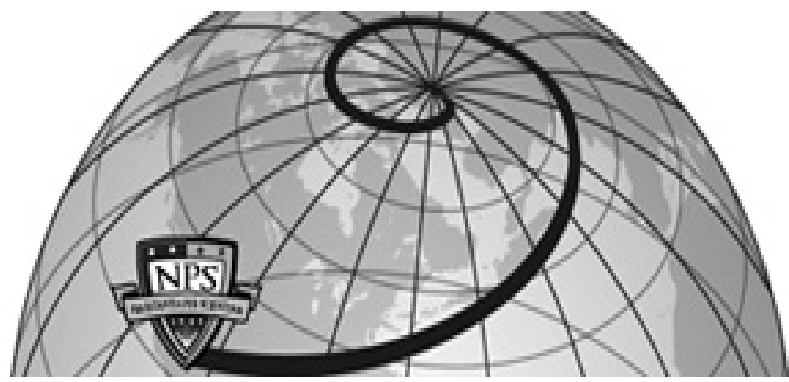

Calhoun: The NPS Institutional Archive DSpace Repository

\title{
Optimal commitment of forces in some Lanchester-type combat models
}

Taylor, James G.

Monterey, California. Naval Postgraduate School

https://hdl.handle.net/10945/29439

This publication is a work of the U.S. Government as defined in Title 17, United States Code, Section 101. Copyright protection is not available for this work in the United States.

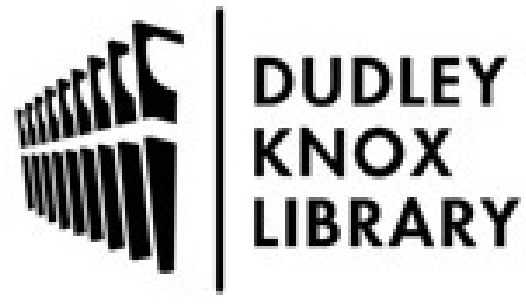

http://www.nps.edu/library
Calhoun is the Naval Postgraduate School's public access digital repository for research materials and institutional publications created by the NPS community. Calhoun is named for Professor of Mathematics Guy K. Calhoun, NPS's first appointed -- and published -- scholarly author.

Dudley Knox Library / Naval Postgraduate School 411 Dyer Road / 1 University Circle Monterey, California USA 93943 
NPS $55-77-2$

\section{NAVAL POSTGRADUATE SCHOOL Monterey, Galifornia}

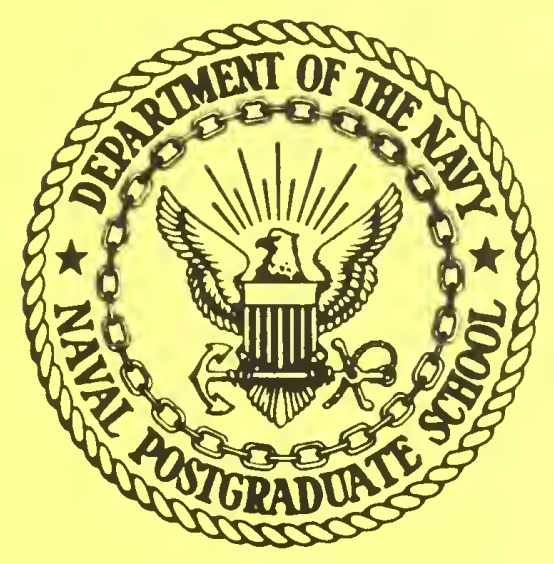

\section{OPTIMAL COMMITMENT OF FORCES}

IN SOME LANCHESTER-TYPE COMBAT MODELS

by

James G. Taylor

Partial Report for Period

September 1976 - December 1976

Approved for public release; distribution unlimited.

Prepared for:

Office of Naval Research, Arlington, Virginia 22217 
NAVAL POSTGRADUATE SCHOOL

Monterey, CA 93940

Rear Admiral Isham Linder

Jack R. Borsting

Superintendent

Provost

This work was supported by the Foundation Research Program of the Naval Postgraduate School with funds provided by the Chief of Naval Research.

Reproduction of all or part of this report is authorized.

This report was prepared by: 


\begin{tabular}{|c|c|}
\hline REPORT DOCUMENTATION PAGE & \multirow{2}{*}{$\begin{array}{l}\text { READ INSTRUCTIONS } \\
\text { BEFORE COMPLETING FORM } \\
\text { 3. RECIPIENT'S CATALOG NUMBER }\end{array}$} \\
\hline \begin{tabular}{l|l|l} 
1. REPORT NUMBER & 2. GOVT ACCESSION NO \\
NPS $55-77-2$ &
\end{tabular} & \\
\hline \multirow{2}{*}{$\begin{array}{l}\text { 4. TITLE (and Subtitle) } \\
\text { OPTIMAL COMMITMENT OF FORCES IN SOME LANCHESTER- } \\
\text { TYPE COMBAT MODELS }\end{array}$} & $\begin{array}{l}\text { 5. TYPE OF REPORT \& PERIOD COVERED } \\
\text { Technical Report--Partial } \\
\text { Report for Sept.-Dec. } 1976\end{array}$ \\
\hline & 6. PERFORMING ORG. REPORT NUMBER \\
\hline $\begin{array}{l}\text { 7. AUTHOR(s) } \\
\text { James G. Taylor }\end{array}$ & 8. CONTRACT OR GRANT NUMBER(s) \\
\hline $\begin{array}{l}\text { 9. PERFORMING ORGANIZATION NAME AND ADDRESS } \\
\text { Naval Postgraduate School } \\
\text { Monterey, CA } 93940\end{array}$ & $\begin{array}{l}\text { 10. PROGRAM ELEMENT. PROJECT, TASK } \\
\text { AREAQ WORK UNIT NUMBERS TASK } \\
6] 152 \mathrm{~N}, \text { RR 000-0]-0] } \\
\text { N0001477WR70044 }\end{array}$ \\
\hline \multirow{4}{*}{$\begin{array}{l}\text { 11. CONTROLLING OFFICE NAME AND ADDRESS } \\
\text { Office of Naval Research } \\
\text { Arlington, VA } 22217 \\
\text { 14. MONITORING AGENCY NAME \& ADDRESS(If different from Controlltng Offlco) }\end{array}$} & $\begin{array}{l}\text { 12. REPORT DATE } \\
\text { January } 1977\end{array}$ \\
\hline & $\begin{array}{l}\text { 13. NUMBER OF PAGES } \\
35\end{array}$ \\
\hline & $\begin{array}{l}\text { 15. SECURITY CLASS. (of this roport) } \\
\text { Unclassified }\end{array}$ \\
\hline & $\begin{array}{l}\text { 15. DECLASIFIFICATION/DOWNGRADING } \\
\text { SECEOULE }\end{array}$ \\
\hline
\end{tabular}

17. DISTRIBUTION STATEMENT (of the abstract onterod in Block 20, if difforont trom Roport)

16. SUPPLEMENTARY NOTES

19. KEY WORDS (Continue on reverse side if necessary and identily by block number)

Lanchester Theory of Combat Combat Dynamics

Tactical Decision Making Deterministic Combat Attrition

Military Decision Analysis

20. ABSTRACT (Continue on reverse elde If neceseery and Identlfy by block number)

This paper shows that one can determine whether or not it is beneficial for the victor to initially commit as many forces as possible to battle in Lanchester-type combat between two homogeneous forces by considering the instantaneous casualty-exchange ratio. It considers the initial-commitment decison as a one-sided static optimization problem and examines this nonlinear program for each of three decision criteria (victor's losses, loss ratio, and loss difference) and for each of two different batcle-termination 
conditions (given force-level breakpoint and given force-ratio breakpoint). The paper's main contribution is to show how to determine the sign of the partial derivative of the decision criterion with respect to the victor's initial force level for general combat dynamics without explicitly solving the Lanchester-type combat equations. Consequently, the victor's optimal initialcommitment decision many times may be determined from how the instantaneous casualty-exchange ratio varies with changes in the victor's force level and time. Convexity of the instantaneous casualty-exchange ratio is shown to imply convexity of the decision criterion so that conditions of decreasing marginal returns may be identified also without solving the combat equations. The optimal initial-commitment decision is shown to be sensitive to the decision criterion for fixed force-ratio breakpoint battles. 


\section{O. INTRODUCTION}

This paper ${ }^{1}$ analyzes the decision to initially commit forces to battle. The combat is modelled by deterministic Lanchester-type equations with two force-level variables. Our results show that it is not always "best" to initially commit as much as possible to battle but that the optimal decision for the initial commitment of forces depends on a number of factors. The key factor in the victor's optimal commitment of forces is how the trading of casualties depends on the victor's force level and time. In contrast to all previous work, however, our results do not depend on explicitly solving the Lanchester-type differential equations but rather on establishing certain properties for the instantaneous casualty-exchange ratio. ${ }^{2}$

In his now classic 1914 paper F. W. Lanchester ${ }^{[9]}$ (1868-1946) sought to develop a quantitative justification for the principle of concentration ${ }^{3}$ with an idealized model of the combat process, and subsequently several other workers (see references $1,6,21,23$, and 24) have considered whether or not concentration of forces is "beneficial." The paper at hand extends previous work by Bach, Dolansky, and Stubbs [1] and Taylor and Parry ${ }^{[21]}$. Bach et al. considered a fight-to-the-finish modelled by Lanchester-type equations of "modern warfare" (see reference 19) with operational losses. Using the overall casualty-exchange ratio as the decision criterion, they showed by explicit computation how the optimal initial commitment of forces depends on a certain parameter $k$ that involves the operational loss rates and the unit effectivenesses. Taylor and Parry ${ }^{[21]}$ pointed out the wider applicability of the model of Bach et al.[1] and simplified their optimal decision rule. Moreover, Taylor and Parry conjectured (but did not prove) that the optimal initial commitment of forces could be determined by considering the instantaneous casualty-exchange ratio and studied the variable-coefficient version of the model of Bach et al.

Thus, the purpose of this paper is to prove the conjecture made by Taylor and Parry ${ }^{[21]}$ that the optimal initial commitment of forces may be determined from how the instantaneous casualty-exchange ratio varies with the victor's force level and 
time. For general Lanchester-type equations of combat between two homogeneous forces, the victor's decision as to how many forces should be initially committed is analyzed as a one-sided combat optimization problem. The initial-commitment decision is evaluated according to three different criteria (victor's losses, loss ratio, and loss difference) and for two sets of battle-termination conditions (battle with fixed forcelevel breakpoint and battle with fixed force-ratio breakpoint), and results are compared. In this work, partial derivatives of the decision criteria with respect to the victor's initial force level are calculated without explicitly solving the Lanchestertype equations. Each of the three decision criteria is shown to be a convex function of the victor's initial force level under the appropriate convexity conditions on the instantaneous casualty-exchange ratio so that circumstances of diminishing marginal returns from committing additional forces may be identified.

\section{Analysis of Decision to Initially Commit Forces}

Let us consider combat between two homogeneous forces described by the following deterministic Lanchester-type equations ${ }^{4}$ for $x, y>0$ [the first equation, for example, becomes $\mathrm{dx} / \mathrm{dt}=0$ for $\mathrm{x}=0$ ]

$$
\begin{cases}d x / d t=-F(t, x, y) & \text { with } x(t=0)=x_{0}, \\ d y / d t=-G(t, x, y) & \text { with } y(t=0)=y_{0},\end{cases}
$$

where $x(t)$ and $y(t)$ denote the $X$ and $Y$ force levels at time $t$, and $F$ and G denote force-change rates (with a negative force-change rate signifying a net influx of replacements). For simplicity we assume that there are no replacements and withdrawals; ${ }^{5}$ and, in this case, $F$ and $G$ are simply casualty rates. To insure the existence of partial derivatives needed in subsequent analysis, we assume that $F(t, x, y)$ and $G(t, x, y)$ are twice continuously differentiable in each of their arguments. The initial force levels at the beginning of battle at $t=0$ are denoted as $\mathrm{x}_{0}$ and $\mathrm{y}_{0}$. Although (1) contains just two force-level variables, this general model does apply to combat between two homogeneous forces with superimposed fire effects of supporting weapons not subject to attrition (see, for example, Taylor and Parry ${ }^{[21]}$ ). 
Let us now consider the decision by the victor in the above battle as to how many of his available forces he should initially comit to combat. This decision is reflected in the model (1) as the victor's choice (within given force limitations) of the value for his initial force level. Without loss of generality we may take $X$ to be the victor (i.e. assume that he has more than enough forces avallable to "win" the battle). [In Section 7 below, we will briefly consider X's initial commitment decision in the face of an enemy victory.] Let us consider the initial-commitment decision by $\mathrm{X}$ as a one-sided combat optimization problem: we assume that the $\mathrm{Y}$-force commander has adopted a known course of action and consider $X^{\prime}$ 's initial commitment decision in this 1ight. This decision is to be made only once, before the battle begins. In other words, we assume that $y_{0}$ is given and seek the "best" value of $x_{0}$ for $x$ to choose. Thus, the decision variable for $x$ in our combat optimization problem is $\mathrm{x}_{0}$, the initial number of forces committed to battle.

It is convenient to consider that there are four fundamental aspects of the onesided combat optimization problem faced by the X-force commander: (1) decision criterion, (2) battle dynamics, (3) battle-termination model, and (4) information structure. In our investigation here let us not consider the inherent uncertainty in the decision problem and assume that $\mathrm{X}$ has perfect knowledge about $\mathrm{x}_{0}$ and $\mathrm{y}_{0}$, the battle dynamics [i.e. equations (1)] (assumed deterministic), and battle termination (also assumed deterministic). ${ }^{6}$ Hence, we will not consider the information structure here further, although it certainly will play a major role in actual real-world military decisions. The purpose of this paper is to show how, in general, the battle dynamics (i.e. the form of equations (1)) influence $X^{\prime}$ s optimal decision.

We assume that the $\mathrm{X}$-force commander bases his decision on a single criterion. Chree possible criteria for evaluating his decision are: (C1) friendly losses, $\mathrm{x}_{\mathrm{X}}=\mathrm{x}_{0}-\mathrm{x}_{\mathrm{f}} ; \quad$ (C2) loss ratio, $\mathrm{R}_{\mathrm{c}}=\left(\mathrm{x}_{0}-\mathrm{x}_{\mathrm{f}}\right) /\left(\mathrm{y}_{0}-\mathrm{y}_{\mathrm{f}}\right)$; and (C3) loss difference, ${ }_{c}=\left(x_{0}-x_{f}\right)-\left(y_{0}-y_{f}\right)$; where $x_{f}$ and $y_{f}$ denote the final force levels at the end if battle at $t=t_{f}$. The latter two criteria have been suggested by Pugh and 
Mayberry [11], who state that the two criteria are "almost equivalent." A major result of this paper is to show that the equivalance of such criteria depends on the battle termination model. Although we are well aware that battle termination is a complex random phenomenon for which it is by no means certain that force levels are the significant variables, ${ }^{7}$ in our analysis here we will consider two types of battle-termination conditions: (T1) battle terminated by $y(t)$ reaching its "breakpoint" force level, $y_{X}^{f} \geq 0$, while $x(t)$ has always been above its "breakpoint" force level, $x_{Y}^{f} \geq 0$; and (T2) battle terminated by $u(t)=x(t) / y(t)$ reaching $Y^{\prime} s$ "breakpoint" force ratio, $u_{X}^{f}>u_{0}=x_{0} / y_{0}$. Analogous conditions may be stated for a $Y$ victory.

We assume that $X$ has limited forces avallable (but more than enough to win). Since all of the decision criteria are basically costs of engagement, he seeks to minimize his adopted objective function by his choice of the value for the decision variable $x_{0}$. Letting $C$ denote one of the above three decision criterla (i.e. either $I_{X}, R_{c}$, or $\left.D_{c}\right)$, we may state our combat optimization problem for the initial commitment of $X^{\prime} s$ forces as

$$
\underset{x_{0}}{\operatorname{minimize} C,} \quad \text { subject to: } x_{0}^{\min } \leq x_{0} \leq x_{0}^{\max } \text {, }
$$

where $x_{0}^{\min }=x_{0}^{d r a w}+\varepsilon, \varepsilon>0$, and $x_{0}^{d r a w}$ denotes the value of the initial $x$ force level which leads to a draw for the given battle-termination conditions (i.e. either (T1) or (T2)). ${ }^{8}$ We denote the optimal value of $x_{0}$ as $x_{0}^{*}$.

The above nonlinear program (2) is trivial to solve after the partial derivative $\partial C / \partial x_{0}$ has been calculated. For example, $\partial C / \partial x_{0}<0 \forall x_{0} \varepsilon\left[x_{0}^{m i n}, x_{0}^{\max }\right]$ implies that $x_{0}^{*}=x_{0}^{\max }$ so that $x$ should initially commit as much as possible. The determination, however, of $\partial C / \partial x_{0}$ requires further analysis. Considering (C1) through (C3) above, we see that calculation of $\partial \mathrm{C} / \partial \mathrm{x}_{0}$ involves determining $\partial \mathrm{x}_{\mathrm{f}} / \partial \mathrm{x}_{0}$, how $\mathrm{X}^{\prime} \mathrm{s}$ final force level varies with changes in his initial force level. 


\section{Dependence of Force Level on Initial Conditions}

We usually take $t$ as the independent variable or time parameter in ( 1 ) and consider $x=x(t), y=y(t)$. For a battle won by $x$, the final $Y$ force level, $y_{f}$, has been driven to satisfy a given battle-termination condition so that the final $\mathrm{X}$ force level depends on this $y_{f}$. Thus, in general we have

$$
x_{f}=x_{f}\left(y_{f} ; x_{0}, y_{0}\right) \quad \text { and } \quad y_{f}=y_{f}\left(x_{0}, y_{0}\right) \text {. }
$$

Hence, for a battle won by $X$ we are motivated to reparameterize the course of battle in terms of $y$ by inverting $y=y(t)$. We must have $d y / d t \neq 0 \forall t \varepsilon\left[0, t_{f}\right]$ to be able to do this, and it seems appropriate to take

$$
\mathrm{dy} / \mathrm{dt}<0 \quad \text { for all } t \in\left[0, \mathrm{t}_{\mathrm{f}}\right]
$$

Accordingly, we have then

$$
t=t(y)=t\left(y ; x_{0}, y_{0}\right) \quad \text { and } \quad x=x(y)=x\left(y ; x_{0}, y_{0}\right)
$$

We next express $x$ in terms of the instantaneous (or differential) casualtyexchange ratio, ${ }^{8} \mathrm{dx} / \mathrm{dy}$. It will sometimes be convenient to use the notation

$$
\Delta=\mathrm{dx} / \mathrm{dy}
$$

In general, we have from (1)

$$
d x / d y=\Delta=\Delta(t, x, y)=F(t, x, y) / G(t, x, y)
$$

When $\Delta$ is time-invariant (i.e. $\partial \Delta / \partial t \equiv 0$ for all $t \geq 0$ ), we will say that the Lanchester-type equations (1) are quasi-autonomous, since they may be transformed to an autonomous system ( $\underline{\text { see p. } 163 \text { of Petrovski }{ }^{[10]} \text { ) by a change of the time scale. }}{ }^{9}$ When $\Delta$ depends on only $t$ and the ratio $x / y$, we will say that Condition (R) holds. Thus, we have

$$
\text { Condition }(R): \quad d x / d y=\Delta=q(t, u), \quad \text { where } u=x / y \text {. }
$$

Je observe that $(\partial \Delta / \partial x)_{t, y}=(1 / y) \partial q / \partial u$ so that $\partial \Delta / \partial x$ and $\partial q / \partial u$ always have the iame sign. Let us further observe that on a partial derivative such as $(\partial \Delta / \partial x)_{t, y}$, 
the subscripts denote the variables being held constant. In terms of our reparameterization (5) in terms of $y$, we have

$$
\Delta=\Delta\left(t\left(y ; x_{0}, y_{0}\right), x\left(y ; x_{0}, y_{0}\right), y\right),
$$

so that we may write

$$
x\left(y ; x_{0}, y_{0}\right)=x_{0}-\int_{y}^{y_{0}} d x / d y\left(t\left(y_{1} ; x_{0}, y_{0}\right), x\left(y_{1} ; x_{0}, y_{0}\right), y_{1}\right) d y_{1} .
$$

Holding $y$ and $y_{0}$ constant and differentiating with respect to $x_{0}$, we obtain

$$
\partial \mathrm{x} / \partial \mathrm{x}_{0}=1-\int^{\mathrm{y}_{0}}\left\{\left(\partial t / \partial \mathrm{x}_{0}\right) \partial \Delta / \partial t+\left(\partial \mathrm{x} / \partial \mathrm{x}_{0}\right) \partial \Delta / \partial \mathrm{x}\right\} \mathrm{dy}_{1},
$$

where $\partial \mathrm{x} / \partial \mathrm{x}_{0}$ denotes $\left(\partial \mathrm{x} / \partial \mathrm{x}_{0}\right)^{\mathrm{y}} \mathrm{y}, \mathrm{y}_{0}$, etc.

The Volterra integral equation (10) may be solved by differentiating with respect to $y$ and integrating the resulting first order linear ordinary differential equation. Setting $y=y_{f}$, we obtain

$$
\begin{aligned}
\partial \mathrm{x}_{\mathrm{f}} / \partial \mathrm{x}_{0}=\left(\partial \mathrm{x}_{\mathrm{f}} / \partial \mathrm{x}_{0}\right)_{\mathrm{y}_{0}, \mathrm{y}_{\mathrm{f}}} & =\exp \left[-\int_{\mathrm{y}_{\mathrm{f}}}^{\mathrm{y}_{0}}(\partial \Delta / \partial \mathrm{x}) \mathrm{dy}\right] \\
& -\int_{\mathrm{y}_{\mathrm{f}}}^{\mathrm{y}_{0}}\left(\partial \mathrm{t} / \partial \mathrm{x}_{0}\right) \partial \Delta / \partial \mathrm{t} \cdot \exp \left[-\int_{\mathrm{y}_{\mathrm{f}}}^{y_{0}}(\partial \Delta / \partial \mathrm{x}) d \mathrm{y}_{1}\right] \mathrm{dy} .
\end{aligned}
$$

Equation (11) relates changes in the final $X$ force level to variations in $X^{\prime}$ 's initial strength. This result (11) is a key one and is used in the development of most subsequent results in this paper.

\section{Derivatives of Decision Criteria}

For the solution of (2) we need to compute $\partial C / \partial x_{0}$ for $C=L_{X}, R_{C}$, and $D_{c}$. As a preliminary step in this computation we recall (3) and observe that

$$
\left(\partial \mathrm{x}_{\mathrm{f}} / \partial \mathrm{x}_{0}\right)_{\mathrm{y}_{0}}=\left(\partial \mathrm{x}_{\mathrm{f}} / \partial \mathrm{x}_{0}\right)_{\mathrm{y}_{0}, \mathrm{y}_{\mathrm{f}}}+\left(\partial \mathrm{x}_{\mathrm{f}} / \partial \mathrm{y}_{\mathrm{f}}\right)_{\mathrm{x}_{0}, \mathrm{y}_{0}} \cdot\left(\partial \mathrm{y}_{\mathrm{f}} / \partial \mathrm{x}_{0}\right)_{\mathrm{y}_{0}},
$$

where $\left(\partial \mathrm{x}_{\mathrm{f}} / \partial \mathrm{x}_{0}\right)_{\mathrm{y}_{0}, \mathrm{y}_{\mathrm{f}}}$ is given by (11). Setting $\mathrm{y}=\mathrm{y}_{\mathrm{f}}$ in (9) so that $\mathrm{x}=\mathrm{x}_{\mathrm{f}}$, holding $x_{0}$ and $y_{0}$ constant, and differentiating the result with respect to $y_{f}$, we obtain 


$$
\left(\partial \mathrm{x}_{\mathrm{f}} / \partial \mathrm{y}_{\mathrm{f}}\right)_{\mathrm{x}_{0}, \mathrm{y}_{0}}=(\mathrm{dx} / \mathrm{dy})_{\mathrm{f}},
$$

where $(d x / d y)_{f}$ denotes the final instantaneous casualty-exchange ratio for $t=t_{f}$, $x=x_{f}$, and $y=y_{f}$. Sometimes for convenience we will denote $(d x / d y)_{f}$ as $\Delta_{f}$ [recall equation (6)]. From (12) and (13), we find that

$$
\left(\partial x_{f} / \partial x_{0}\right)_{y_{0}}=\left(\partial x_{f} / \partial x_{0}\right)_{y_{0}, y_{f}}+(d x / d y)_{f} \cdot\left(\partial y_{f} / \partial x_{0}\right)_{y_{0}} \cdot
$$

Henceforth, we will omit denoting which variables are being held constant in such partial derivatives and hope that this will be clear from context. When $X$ wins, we have via (3) that

$$
\begin{gathered}
\partial L_{\mathrm{f}} / \partial \mathrm{x}_{0}=1-\partial \mathrm{x}_{\mathrm{f}} / \partial \mathrm{x}_{0}-(\mathrm{dx} / \mathrm{dy})_{\mathrm{f}} \partial \mathrm{y}_{\mathrm{f}} / \partial \mathrm{x}_{0}, \\
\partial \mathrm{R}_{\mathrm{c}} / \partial \mathrm{x}_{0}=\left\{1-\partial \mathrm{x}_{\mathrm{f}} / \partial \mathrm{x}_{0}+\left[\mathrm{R}_{\mathrm{c}}-(\mathrm{dx} / \mathrm{dy})_{\mathrm{f}}\right] \partial \mathrm{y}_{\mathrm{f}} / \partial \mathrm{x}_{0}\right\} /\left(\mathrm{y}_{0}-\mathrm{y}_{\mathrm{f}}\right), \\
\partial \mathrm{D}_{\mathrm{c}} / \partial \mathrm{x}_{0}=1-\partial \mathrm{x}_{\mathrm{f}} / \partial \mathrm{x}_{0}+\left[1-(\mathrm{dx} / \mathrm{dy})_{\mathrm{f}}\right] \partial \mathrm{y}_{\mathrm{f}} / \partial \mathrm{x}_{0} .
\end{gathered}
$$

For the case of a fixed final force-level battle in which $y_{f}=y_{X}^{f}$ is fixed beforehand, the above partial derivatives, of course, simplify considerably.

\section{Results for Fixed Force-Level Breakpoint Battle} In this case $\partial y_{f} / \partial x_{0}=0$, and (15) through (17) simplify to

$$
\partial L_{X} / \partial x_{0}=\partial D_{c} / \partial x_{0}=1-\partial x_{f} / \partial x_{0}
$$

ind

$$
\partial R_{c} / \partial x_{0}=\left(1-\partial x_{f} / \partial x_{0}^{\prime}\right) /\left(y_{0}-y_{f}\right)
$$

ihus, all three decision-criterion partial derivatives have the same sign. Consequently, or a fixed force-level breakpoint battle, the $\mathrm{X}$-force commander makes the same decision egardless of which decision criterion he uses. It suffices, therefore, to consider $\mathrm{L}_{\mathrm{X}} / \partial \mathrm{x}_{0}$ in subsequent developments in this section.

By (11) and (18), we have

$$
\begin{aligned}
& \partial \mathrm{L}_{\mathrm{X}} / \partial \mathrm{x}_{0}=1-\exp \left[-\int_{\mathrm{y}_{\mathrm{f}}}^{\left.\mathrm{y}_{0}(\partial \Delta / \partial \mathrm{x}) \mathrm{dy}\right]}\right. \\
& \quad+\int_{\mathrm{y}_{\mathrm{F}}}^{\mathrm{y}_{0}}\left(\partial t / \partial \mathrm{x}_{0}\right) \partial \Delta / \partial t \cdot \exp \left[-\int_{\mathrm{y}_{\mathrm{f}}}^{\mathrm{y}}(\partial \Delta / \partial \mathrm{x}) \mathrm{dy} \mathrm{y}_{1}\right] \mathrm{dy} .
\end{aligned}
$$


We assume that we always have

$$
\left(\partial t / \partial x_{0}\right)_{y, y_{0}}<0
$$

This assumption seems reasonable, since we would expect that higher $\mathrm{x}_{0}$ yields lower $y$ for fixed $y_{0}$ and $t$. Consequently, we may conclude

THEOREM 1: If $\partial(\mathrm{dx} / \mathrm{dy}) / \partial \mathrm{x}<0$ and $\partial(\mathrm{dx} / \mathrm{dy}) / \partial t \geq 0$ for all $t \varepsilon\left[0, t_{\mathrm{f}}\right]$, then $\partial C / \partial x_{0}<0$ for $C=L_{X}, R_{c}, D_{c}$.

Proof: Immediate by (20) and (21).

Q.E.D.

The following theorem shows that under its stated conditions when $q(u)$ is convex and $\partial \mathrm{C} / \partial \mathrm{x}_{0}<0 \forall \mathrm{x}_{0} \varepsilon\left[\mathrm{x}_{0}^{\min }, \mathrm{x}_{0}^{\max }\right]$, there are decreasing marginal returns from initially committing additional forces to battle. The theorem generalizes results given for a specific model by Bach et al. (see p. 320 and p. 325 of reference 1).

THEOREM 2: Consider a battle with a fixed force-level breakpoint to be won by $X$. Assume that Condition (R) holds and that the . Lanchester-type equations (1) are quasi-autonomous. If $\mathrm{dx} / \mathrm{dy}=\mathrm{q}(\mathrm{u}$ ) is a strictly convex (concave) function of $\mathrm{u}$ on $[0,+\infty)$, then the decision criterion $C$ is a strictly convex (concave) function of $x_{0}$ for $C=L_{X}, R_{c}, D_{c}$.

Proof: Computing $\partial^{2} x_{f} / \partial x_{0}^{2}=-\exp \left[-\int_{y_{f}}^{y}(1 / y)(\partial q / \partial u) d y\right] \int_{y_{f}}^{y_{\rho}}\left(1 / y^{2}\right)\left(\partial^{2} q / \partial u^{2}\right) \cdot$ $\exp \left[-\int^{y_{\rho}}\left(1 / y_{1}\right)(\partial q / \partial u) d y_{1}\right] d y$, we see that $\partial^{2} q / \partial u^{2}>0$ implies that $\partial^{2} x_{f} / \partial x_{0}^{2}<0$, whence ${ }^{y}$ the theorem follows from (18) and (19). Q.E.D.

Comment 1: For quasi-autonomous Lanchester-type models we have that $\partial(\mathrm{dx} / \mathrm{dy}) / \partial \mathrm{x}<0$ for all $t \varepsilon\left[0, t_{f}\right]$ implies $\partial C / \partial x_{0}<0$. 
Comment 2: From (20) and (21) we see that, in general, $\partial(\mathrm{dx} / \mathrm{dy}) / \partial \mathrm{x}<0$ for all $t \varepsilon\left[0, t_{f}\right]$ may not always imply $\partial \mathrm{c} / \partial \mathrm{x}_{0}<0$ when $\partial(\mathrm{dx} / \mathrm{dy}) / \partial t<0$. In other words, even though a higher $\mathrm{X}$ force level reduces the instantaneous casualty-exchange ratio (i.e. the cost to $X$ of reducing the $Y$ force level a unit amount), it may not be best for $\mathrm{X}$ to initially commit as many forces as possible when (for constant force levels) the instantaneous casualty-exchange ratio decreases over time. The reason for this result is that smaller $x_{0}$ means that the battle (which $X$ will win by assumption) will last longer, and the longer the battle lasts, the better the instantaneous casualty-exchange ratio becomes for $X$. Let us give an example of this phenomenon.

Example of $\partial C / \partial x_{0}>0$ even though $\partial(d x / d y) / \partial x<0$.

Let us consider Helmbold's[8] modification of Lanchester's classic combat formulation to account for inefficiencies of scale for the larger force when force sizes are grossly unequal. We have for time-varying fire effectivenesses (see Taylor and 3rown [19] for a discussion of modelling considerations regarding variable coefficients and further references)

$$
d x / d t=-a(t)(x / y)^{c} y, \quad d y / d t=-b(t)(y / x)^{c} x
$$

where $c$ is a parameter controlling the relative force-attrition capability. We observe hat $c=0$ corresponds to the usual Lanchester-type equations of modern warfare with ariable attrition-rate coefficients. ${ }^{10}$ We readily compute that

$$
\partial(d x / d y) / \partial x=(1-d)\{a(t) / b(t)\}(x / y)^{-d / y},
$$

there $d=2(1-c)$. Note that $d \leq 2$ for $c \geq 0$. From (23) we see that $\partial(d x / d y) / \partial x<0$ :or $d>1$. We will show by numerical counterexample that Theorem 1 is in general not rue if the assumption that $\partial(\mathrm{dx} / \mathrm{dy}) / \partial t \geq 0$ is omitted. This result, unfortunately, hows that the conclusion drawn about concentration of forces by Taylor and Parry [21] ay not be true in general for variable attrition-rate coefficients. Theorem 1 , however, ;ives sufficient conditions for $\partial C / \partial x_{0}<0$; and for certain battle dynamics, the 
assumption about $\partial(\mathrm{dx} / \mathrm{dy}) / \partial t$ may not be absolutely necessary for the theorem to be true. In other cases, it may be possible to weaken this assumption, but we have not investigated this matter further.

Let $a(t)$ and $b(t)$ be piecewise constant ${ }^{10}$ and denote

$$
a(t) / b(t)= \begin{cases}a / b & \text { for } 0 \leq t<t_{c}, \\ \tilde{a} / \tilde{b} & \text { for } t \geq t_{c},\end{cases}
$$

where ${ }_{c}$ denotes the time at which the relative effectiveness of combatants changes. We will consider the case in which $a / b>\tilde{a} / \tilde{b}$. This case may be regarded as an approxi mation to that in which $\partial(\mathrm{dx} / \mathrm{dy}) / \partial t<0$. For a battle terminated by a given forcelevel "breakpoint" being reached, $x$ wins when $t_{f} \leq t_{c}$ if and only if

$$
\left(u_{0}\right)^{d}>a\left(1-f_{Y}^{d}\right) /\left[b\left(1-f_{X}^{d}\right)\right] \text {, }
$$

where, for example, $x_{Y}^{f}=f_{X} x_{0}$ and $x_{Y}^{f}$ denotes the $X$ "breakpoint" for a $Y$ victory Analytic results that are required for this investigation are given in Table I. Numerj cal results are shown in Table II. The $\mathrm{X}$ force "wins" all three battles. From Table II we see that decreasing $u_{0}$ (i.e. decreasing $x_{0}$ for fixed $y_{0}$ ) actually leads to a more favorable casualty exchange ratio for $x$, even though $\partial(d x / d y) / \partial x<0$. The reason for this result is that reducing the initial force ratio extends the length of battle, and the battle is then fought for $t>t_{c}$ at greater relative effectivenes: per man from $X^{\prime}$ s standpoint (i.e. $\left.\tilde{b} / \tilde{a}>b / a\right)$. For the classic equations of "modern warfare" (i.e. $d=2$ ), we have not been able to find any such counterexample. We sti feel, however, that for this case with variable attrition-rate coefficients Theorem 1 is probably false without the assumption that $\partial(\mathrm{dx} / \mathrm{dy}) / \partial t \geq 0$.

\section{Results for Fixed Force-Ratio Breakpoint Battle}

For a battle terminated by $u(t)$ reaching a given "breakpoint" force ratio ${ }^{12}$ w! obtain using (3) that when $\mathrm{X}$ wins ${ }^{13}$

$$
\partial y_{f} / \partial x_{0}=\left(\partial x_{f} / \partial x_{0}\right) /\left(u_{x}^{f}-\Delta_{f}\right)
$$

where $\Delta_{f}$ denotes $(d x / d y)_{f}$ and we recall that $u_{X}^{f}$ is a given constant. Observing that (see Taylor ${ }^{[17]}$ ) 
TABLE I.

ANALYTIC RESULTS FOR HELMBOLD'S MODEL USED IN EXAMPLE

1. For $^{11} \mathrm{t}_{\mathrm{f}} \leq \mathrm{t}_{\mathrm{c}}$

$$
t_{f}=\left[2 /(d \sqrt{a b)}] \ln \left\{\left[\sqrt{\left(u_{0}\right)^{d}-(a / b)\left(1-f_{Y}^{d}\right)}-f_{Y}^{d / 2} \sqrt{a / b}\right] /\left[\left(u_{0}\right)^{d / 2}-\sqrt{a / b}\right]\right\}\right.
$$

2. For $t_{f} \leq t_{c}$

$$
R_{c}=\left\{u_{0}-\left[\left(u_{0}\right)^{d}-(a / b)\left(1-f_{Y}^{d}\right)\right]^{1 / d}\right\} /\left(1-f_{Y}\right)
$$

3. For $t_{f}>t_{c}$

$$
R_{c}=\left\{u_{0}-\left[\left(u_{0}\right)^{d}-(a / b)\left\{1-\left(y_{c} / y_{0}\right)^{d}\right\}-(\tilde{a} / \tilde{b})\left\{\left(y_{c} / y_{0}\right) d-f_{Y}^{d}\right\}\right]^{1 / d}\right\} /\left(1-f_{Y}\right)
$$

where

$$
\left(y_{c} / y_{0}\right)^{d}=\left\{\cosh \left(\sqrt{a b} t_{c} d / 2\right)-\left(u_{0}\right) d / 2 \sqrt{b / a} \sinh \left(\sqrt{a b} t_{c} d / 2\right)\right\}^{2}
$$

4. For $t_{f}>t_{c}$

$$
\partial \mathrm{R}_{\mathrm{C}} / \partial \mathrm{x}_{0}=\left(1-\mathrm{F}_{\mathrm{N}} / \mathrm{F}_{\mathrm{D}}\right) /\left[\left(1-\mathrm{f}_{\mathrm{Y}}\right) \mathrm{y}_{0}\right]
$$

where

$$
\begin{aligned}
& F_{N}=1-\left(1 / u_{0}^{d / 2}\right) \sqrt{\left(y_{c} / y_{0}\right) d_{b}^{d} / a}\{(a / b)-(\tilde{a} / \tilde{b})\} \sinh \left(\sqrt{a b} t_{c} d / 2\right) \\
& F_{D}=\left\{1-\left[(a / b)\left\{1-\left(y_{c} / y_{0}\right){ }^{d}\right\}+(\tilde{a} / \tilde{b})\left\{\left(y_{c} / y_{0}\right)^{d}-f_{Y}^{d}\right\}\right] / u_{0}^{d}\right\}(d-1) / d
\end{aligned}
$$

Note: The above results hold for $d \neq 0$. 
TABLE II.

NUMERICAL RESULTS WHICH SHOW THAT $\partial(d x / d y) / \partial x<0$ DOES NOT ALWAYS IMPLY THAT $\partial \mathrm{R}_{c} / \partial \mathrm{x}_{0}<0$.

\begin{tabular}{|c|c|c|c|c|c|c|}
\hline Battle & $u_{0}$ & $t_{f}$ & $t_{c}$ & $y_{c} / y_{0}$ & $R_{c}$ & $\partial R_{c} / \partial x_{0}+$ \\
\hline 1 & 4.0 & 19.5 & 20.0 & -- & 0.437 & -- \\
2 & 2.0 & $t_{c}<t_{f}$ & 20.0 & 0.69 & 0.434 & $(0.0112) / y_{0}$ \\
3 & 1.0 & $t_{c}<t_{f}$ & 20.0 & 0.82 & 0.420 & $(0.0122) / y_{0}$ \\
\hline
\end{tabular}

Other parameter values (time expressed in the same units for a, $t_{f}$, and $\left.t_{c}\right):$

$\mathrm{d}=1.5, \quad \mathrm{f}_{\mathrm{Y}}=0.5, \quad \mathrm{a}=0.01, \quad \mathrm{a} / \mathrm{b}=1.0, \quad \tilde{\mathrm{a}} / \tilde{\mathrm{b}}=0.1$

${ }^{\dagger}$ Computed using result 4 of Table $I$. 


$$
u-\Delta=(d u / d t) /\{-(1 / y) d y / d t\}
$$

we see by (4) that

$$
u_{X}^{f}-\Delta_{f}>0 \Leftrightarrow X \text { wins. }
$$

By (25) and (27) we see that $\partial x_{f} / \partial x_{0}$ and $\partial y_{f} / \partial x_{0}$ have the same sign when $x$ wins. Using (25), we find that (15) through (17) become

$$
\begin{gathered}
\partial L_{X} / \partial x_{0}=1-\left\{1 /\left(1-\Delta_{f} / u_{X}^{f}\right)\right\} \partial x_{f} / \partial x_{0}, \\
\partial R_{c} / \partial x_{0}=\left\{1-\left[\left(u_{x}^{f}-R_{c}\right) /\left(u_{x}^{f}-\Delta_{f}\right)\right] \partial x_{f} / \partial x_{0}\right\} /\left(y_{0}-y_{f}\right), \\
\partial D_{c} / \partial x_{0}=1-\left\{\left(u_{X}^{f}-1\right) /\left(u_{X}^{f}-\Delta_{f}\right)\right\} \partial x_{f} / \partial x_{0},
\end{gathered}
$$

where we recall that $\partial \mathrm{x}_{\mathrm{f}} / \partial \mathrm{x}_{0}$ is given by (11). We observe that (28) through (30) reduce to (18) and (19) for $u_{X}^{f}=+\infty$, which is a "fight-to-the-finish." We will now show that the three criteria do not all lead to the same initial-comitment decision.

Let us first consider the criterion of only the friendly losses. If $x_{0}^{\max } \geq y_{0} u_{x}^{f}$, then clearly $x_{0}^{*}=x_{0}^{\max }$ and $L_{X}=0$. Let us therefore, assume that $\mathrm{x}_{0}^{\max }<\mathrm{y}_{0} \mathrm{u}_{\mathrm{X}}^{\mathrm{f}}$. Recalling (27), we see from (28) that $\partial \mathrm{L}_{\mathrm{X}} / \partial \mathrm{x}_{0}<1-\partial \mathrm{x}_{\mathrm{f}} / \partial \mathrm{x}_{0}$ so that recalling (11) we have

THEOREM 3: Consider a battle with a flxed force-ratio breakpoint to be won by $\mathrm{x}$. If $\partial(\mathrm{dx} / \mathrm{dy}) / \partial \mathrm{x} \leq 0$ and $\partial(\mathrm{dx} / \mathrm{dy}) / \partial t \geq 0$ for all $t \in\left[0, \mathrm{t}_{\mathrm{f}}\right]$, then $\partial \mathrm{L}_{\mathrm{X}} / \partial \mathrm{x}_{0}<0$.

As seem from Theorem 3, it is advantageous for $X$ to inftially commlt as many forces as possible even for a quasi-autonomous "linear-law" attrition process for which $\partial \Delta / \partial \mathrm{x} \equiv 0 \equiv \partial \Delta / \partial t$. A numerical example of this phenomenon is shown in Table III. We observe that for a fixed force-level breakpoint battle, there is no advantage to $\mathrm{X}$ from inftially committing additional forces over those required to win for this attrition structure. 
TABLE III.

EXAMPLE OF BENEFIT TO $X$ FROM INITIALLY COMMITTING MORE FORCES IN QUASI-AUTONOMOUS LINEAR-LAW BATTLE WITH FIXED FORCE-RATIO BREAKPOINT.

State Equation for Battle: $b\left(x_{0}-x\right)=a\left(y_{0}-y\right)$

\begin{tabular}{|c|c|c|c|}
\hline Battle & $\mathrm{x}_{0}$ & $\mathrm{~L}_{\mathrm{X}}$ & $\mathrm{R}_{\mathrm{C}}$ \\
\hline 1 & 150.0 & 83.33 & 1.0 \\
2 & 200.0 & 66.67 & 1.0 \\
3 & 300.0 & 33.33 & 1.0 \\
\hline
\end{tabular}

Other parameter values:

$$
b / a=1.0, \quad u_{x}^{f}=4.0, \quad y_{0}=100.0
$$


When the casualty-exchange ratio $R_{c}$ is taken as the decision criterion, the decision to initially commit forces is essentially independent of the battle-termination conditions. Before we formally state this result, it is convenient to define the following condition:

$$
\text { Condition }(G) \text { : } \quad R_{c}=R_{c}\left(u_{x}^{f}\right)>(d x / d y)_{f}=\Delta_{f}\left(u_{X}^{f}\right) \text { for all } u_{X}^{f} \varepsilon\left(u_{0},+\infty\right) \text {. }
$$

We have then

THEOREM 4: Assume that Conditions $(G)$ and $(R)$ hold. If $\partial(\mathrm{dx} / \mathrm{dy}) / \partial \mathrm{x}<0$ and $\partial(\mathrm{dx} / \mathrm{dy}) / \partial t \geq 0$ for all $t \varepsilon\left[0, t_{f}\right]$, then $\partial \mathrm{R}_{\mathrm{c}} / \partial \mathrm{x}_{0}<0$.

Proof: Considering $\frac{f}{u_{x}}-R_{c}=\left(u_{x}^{f}-u_{0}\right) /\left(1-y_{f} / y_{0}\right)$, we see that

$$
u_{X}^{f}>R_{c} \Leftrightarrow x \text { wins. }
$$

Now consider $N\left(u_{X}^{f}\right)=N\left(u_{X}^{f}, t_{f}\left(u_{X}^{f}\right), y_{f}\left(u_{X}^{f}\right)\right)$ for $u_{Y}^{f}<u_{0} \leq u_{X}^{f}<+\infty$, where

$$
N\left(u_{X}^{f}\right)=1-\left\{\left(u_{X}^{f}-R_{C}\right) /\left(u_{X}^{f}-\Delta_{f}\right)\right\} \partial x_{f} / \partial x_{0} .
$$

We then have by (29)

$$
\partial R_{c} / \partial x_{0}=N\left(u_{x}^{f}\right) /\left(y_{0}-y_{f}\right)
$$

The theorem follows from (34) by showing that $N\left(u_{X}^{f}\right)<0$ for $u_{0}<u_{X}^{f}<+\infty$. The latter result will be proven by showing that (a) $N\left(u_{X}^{f}=u_{0}\right)=0$, and (b) $d N / d u_{X}^{f}<0$ for $u_{0}<\frac{f}{x}<+\infty$.

To show that

$$
\lim _{\substack{f \\ u_{x} \rightarrow u_{0}}} N\left(u_{x}^{f}\right)=0=N\left(u_{x}^{f}=u_{0}\right)
$$

we observe that $\quad \lim _{f}=y_{0}$ and

$$
\begin{aligned}
& \underset{u_{X}^{f}}{f} \rightarrow u_{0} \\
& \lim _{\substack{f \\
u_{x} \rightarrow u_{0}}} N\left(u_{X}^{f}\right)=1-\lim _{\substack{u_{x} \rightarrow u_{0}}}\left\{u_{X}^{f}-R_{c}\right\} /\left\{u_{X}^{f}-(d x / d y)_{f}\right\} .
\end{aligned}
$$

Using L'Hospital's rule, we readily compute $\lim _{\mathrm{f}} \mathrm{R}_{\mathrm{c}}=\lim \left\{\int_{\mathrm{y}_{\mathrm{f}} \rightarrow \mathrm{y}_{0}}^{\mathrm{y}_{0}}(\mathrm{dx} / \mathrm{dy}) \mathrm{dy}\right\} /\left(\mathrm{y}_{0}-\mathrm{y}_{\mathrm{f}}\right)$

$=(\mathrm{dx} / \mathrm{dy})_{\mathrm{f}}$, whence (35) follows from (36). $u_{\mathrm{x}} \rightarrow \mathrm{u}_{0} \quad \mathrm{y}_{\mathrm{f}} \mathrm{ry}_{0} \mathrm{y}_{\mathrm{f}}$ 
We next show that $d N / d u_{X}^{f}<0$ for $u_{0}<u_{X}^{f}<+\infty$. First, we compute $d N / d u_{X}^{f}$ from (33) to obtain

$$
\begin{aligned}
& \mathrm{dN} / \mathrm{d} \mathrm{u}_{\mathrm{X}}^{\mathrm{f}}=\left\{1 /\left(u_{\mathrm{X}}^{\mathrm{f}}-\Delta_{\mathrm{f}}\right)\right\}\left\{-1+\mathrm{d} \mathrm{R}_{\mathrm{c}} / d \mathrm{u}_{\mathrm{X}}^{\mathrm{f}}+\left(\mathrm{u}_{\mathrm{X}}^{\mathrm{f}}-\mathrm{R}_{\mathrm{c}}\right)\left(1-\mathrm{d} \Delta_{\mathrm{f}} / \mathrm{d} \mathrm{u}_{\mathrm{X}}^{\mathrm{f}}\right) /\left(\mathrm{u}_{\mathrm{X}}^{\mathrm{f}}-\Delta_{\mathrm{f}}\right)\right\}\left(\partial \mathrm{x}_{\mathrm{f}} / \partial \mathrm{x}_{0}\right) \\
& -\left[\left(u_{X}^{f}-R_{c}\right) /\left(u_{x}^{f}-\Delta_{f}\right)\right] d\left(\partial x_{f} / \partial x_{0}\right) / d u_{X}^{f} .
\end{aligned}
$$

Considering the definition of $R_{c}$, (3), and (26), one may show that ${ }^{14}$

$$
\mathrm{dR}_{\mathrm{c}} / d u_{\mathrm{X}}^{\mathrm{f}}=-\mathrm{y}_{\mathrm{f}}\left(\mathrm{R}_{\mathrm{c}}-\Delta_{\mathrm{f}}\right) /\left\{\left(\mathrm{y}_{0}-\mathrm{y}_{\mathrm{f}}\right)\left(\mathrm{u}_{\mathrm{X}}^{\mathrm{f}}-\Delta_{\mathrm{f}}\right)\right\} \text {. }
$$

Recalling that $y_{f}=y_{f}\left(u_{x}^{f}\right)$, we obtain from (11) that

$$
d\left(\partial x_{f} / \partial x_{0}\right) / d u_{X}^{f}=\left\{\left(\partial \Delta_{f} / \partial x_{f}\right) \partial x_{f} / \partial x_{0}+\left(\partial \Delta_{f} / \partial t_{f}\right) \partial t_{f} / \partial x_{0}\right\} d y_{f} / d u_{X}^{f},
$$

where $d y_{f} / d u_{X}^{f}=-y_{f} /\left(u_{X}^{f}-\Delta_{f}\right)<0$. By Condition $(R)$ we have $d \Delta_{f} / d u_{X}^{f}=\partial \Delta_{f} / \partial u_{X}^{f}+$ $\left(\partial \Delta_{f} / \partial t_{f}\right) d t_{f} / d u_{X}^{f}$.' Observing that $y_{f} \cdot\left(\partial \Delta_{f} / \partial x_{f}\right)_{t_{f}, y_{f}}=\left(\partial \Delta_{f} / \partial u_{X}^{f}\right)_{f}, y_{f}$, we may combine (37) and (39) to obtain

$$
\begin{aligned}
d N / d u_{X}^{f}=\left\{1 /\left(u_{X}^{f}-\Delta_{f}\right)\right\}\left\{-1+d R_{c} / d u_{X}^{f}\right. & \left.+\left(u_{X}^{f}-R_{c}\right) /\left(u_{X}^{f}-\Delta_{f}\right)\right\} \partial x_{f} / \partial x_{0} \\
& +\Phi \cdot\left(u_{X}^{f}-R_{c}\right) /\left(u_{X}^{f}-\Delta_{f}\right)^{2}
\end{aligned}
$$

where $\Phi=\left\{\mathrm{y}_{\mathrm{f}} \cdot \partial t_{\mathrm{f}} / \partial \mathrm{x}_{0}-\left(\mathrm{dt} / \mathrm{du} \mathrm{f}_{\mathrm{f}}^{\mathrm{f}}\right) \partial \mathrm{x}_{\mathrm{f}} / \partial \mathrm{x}_{0}\right\} \partial \Delta_{\mathrm{f}} / \partial t_{\mathrm{f}}$. We observe that $\Phi \leq 0$, since $\partial \mathrm{x}_{\mathrm{f}} / \partial \mathrm{x}_{0}>0, \mathrm{du} \mathrm{f}_{\mathrm{f}}^{\mathrm{f}} / \mathrm{dt} \mathrm{f}_{\mathrm{f}}>0$, and by assumption $\partial \Delta_{\mathrm{f}} / \partial \mathrm{t}_{\mathrm{f}} \geq 0$ and $\partial \mathrm{t}_{\mathrm{f}} / \partial \mathrm{x}_{0}<0$ [see (21) above]. It follows by (27), (32), (38), and (40) that for $u_{0}<u_{X}^{f}<+\infty$

$$
d N / d u_{X}^{f} \leq\left\{-y_{0}\left(R_{c}-\Delta_{f}\right) /\left[\left(u_{X}^{f}-\Delta_{f}\right)^{2}\left(y_{0}-y_{f}\right)\right]\right\} \partial x_{f} / \partial x_{0}<0
$$

the last inequality being a consequence of Condition (G).

Q.E.D

It may be difficult to determine, in general, whether Condition (G) holds.

However, it does hold for quasi-autonomous Lanchester-type equations when Condition (1) holds and $\partial \Delta / \partial u<0$ always. Thus, we have

LEMMA 1: When Condition ( $R$ ) holds for quasi-autonomous Lanchester-type equations, then $\partial \Delta / \partial u<0$ for all $t \varepsilon\left[0, t_{f}\right]$ implies $R_{c}>\Delta_{f}$ (i.e. Condition (G) holds). 
Proof: By the assumptions, $u<\mathrm{u}_{\mathrm{X}}^{\mathrm{f}}$ implies $\Delta>\Delta_{\mathrm{f}}$ whence follows the lemma by considering $R_{c}-\Delta_{f}=\int_{y_{f}}\left(\Delta-\Delta_{f}\right) d y /\left(y_{0}-y_{f}\right) . \quad$ Q.E.D.

Then for quasi-autonomous Lanchester-type equations when Condition ( $R$ ) holds and the casualty-exchange ratio is taken as the decision criterion, the decision to initially commit forces is independent of the battle-termination conditions.

COROLLARY 4.1: Assume that Condition ( $R$ ) holds for quasi-autonomous

Lanchester-type equations. For a battle with either a

fixed force-level breakpoint or a fixed force-ratio

breakpoint, if $\partial \Delta / \partial x<0$ for all $t \varepsilon\left[0, t_{f}\right]$, then

$\partial R_{c} / \partial x_{0}<0$.

Proof: By Theorem 1 the result is true for a battle with a fixed force-level breakpoint. For a battle with a fixed force-ratio breakpoint, we know that Condition (G) holds by Lemma 1 so that the corollary follows by observing that all the assumptions of Theorem 4 are satisfied.

Q.E.D.

Finally, we consider the loss difference $D_{c}$ as the decision criterion for initially committing forces. A general result, however, is only available when the final differential casualty-exchange ratio is greater than one.

THEOREM 5: If $\partial(\mathrm{dx} / \mathrm{dy}) / \partial \mathrm{x}<0$ and $\partial(\mathrm{dx} / \mathrm{dy}) / \partial t \geq 0$ for all $t \varepsilon\left[0, t_{\mathrm{f}}\right]$ and $(d x / d y)_{f} \geq 1$, then $\partial D_{c} / \partial x_{0}<0$.

Proof: Recalling (11) and (21), we see that the assumptions of the theorem yield $\partial \mathrm{x}_{\mathrm{f}} / \partial \mathrm{x}_{0}>0$. Recalling (27) and (30), we then see that $\Delta_{\mathrm{f}} \geq 1$ implies that $\partial D_{c} / \partial x_{0} \leq 1-\exp \left\{-\int_{y_{f}}^{y_{0}}(\partial \Delta / \partial x) d y\right\}$ whence follows the theorem. Q.E.D.

If $\Delta_{f}<1$, however, it does not follow by the other stated conditions of Theorem 5 that $\partial D_{c} / \partial x_{0}<0$ so that $x_{0}^{*}=x_{0}^{\max }$ : it is possible for $x_{0}^{*}$ to be an interior point of the interval $\left[\mathrm{x}_{0}^{\min }, \mathrm{x}_{0}^{\max }\right]$ (i.e. $\mathrm{D}_{\mathrm{c}}$ has an unconstrained global minimum at $x_{0}^{*}$ such that $x_{0}^{m i n}<x_{0}^{*}<x_{0}^{\max }$ ). Before we give an example of this 
occurrence, however, let us give results analogous to those of Theorem 2, which applies for a fixed force-level breakpoint.

THEOREM 6: Consider a battle with a fixed force-ratio breakpoint to be won by $X$. Assume that Condition ( $R$ ) holds and that the Lanchester-type equations (1) are quasi-autonomous. If $\mathrm{dx} / \mathrm{dy}=\mathrm{q}(\mathrm{u})$ is a strictly convex (concave) function of $u$ on $[0,+\infty$ ) and $(\partial \mathrm{q} / \partial \mathrm{u})_{\mathrm{f}}<0(>0)$, then $\mathrm{L}_{\mathrm{X}}$ is a strictly convex (concave) function of $x_{0}$. The same is true for $R_{c}$ if additionally $\partial \mathrm{R}_{\mathrm{c}} / \partial \mathrm{x}_{0}<0 \quad \forall \mathrm{x}_{0} \varepsilon\left[\mathrm{x}_{0}^{\min }, \mathrm{x}_{0}^{\max }\right]$, while it is true for $\mathrm{D}_{\mathrm{c}}$ if $u_{\mathrm{X}}^{\mathrm{f}}>1$

Proof: Computing $\partial^{2} x_{f} / \partial x_{0}^{2}=-\int_{y_{f}}^{y_{f}}\left(1 / y^{2}\right)\left(\partial^{2} q / \partial u^{2}\right) \exp \left[\int_{f}^{y_{f}}\left(1 / y_{1}\right)(\partial q / \partial u) d y_{1}\right] d y$ $\left.-\left(1 / y_{f}\right)(\partial q / \partial u)_{f} /\left(u_{X}^{f}-\Delta_{f}\right)\right\} \cdot \exp \left[-2 \int_{y_{f}}^{y_{0}^{f}}(1 / y)(\partial q / \partial u) d y\right]$, we see that $x_{f}$ is a strictly concave (convex) function of $x_{0}$ under the stated conditions. The theorem readily follows after we compute $\partial^{2} L_{X} / \partial x_{0}^{2}=1-\left\{1 /\left(1-\Delta_{f} / u_{X}^{f}\right)\right\} \partial^{2} x_{f} / \partial x_{0}^{2}, \quad \partial^{2} R_{c} / \partial x_{0}^{2}=$ $\left\{2\left(\partial R_{c} / \partial x_{0}\right) \partial x_{f} / \partial x_{0}-\left(u_{X}^{f}-R_{c}\right) \partial^{2} x_{f} / \partial x_{0}^{2}\right\} /\left\{\left(y_{0}-y_{f}\right)\left(u_{X}^{f}-\Delta_{f}\right)\right\}$, and $\partial^{2} D_{c} / \partial x_{0}=$ $1-\left\{\left(u_{X}^{f}-1\right) /\left(u_{x}^{f}-\Delta_{f}\right)\right\} \partial^{2} x_{f} / \partial x_{0}^{2}$.

We now give an example that an unconstrained optimal initial force level (for fixed $y_{0}$, equivalently, an unconstrained optimal initial force ratio $u_{0}^{*}$ ) can occur when $D_{c}$ is the decision criterion. Let us first note that it is possible for $\partial D_{C} / \partial x_{0}=0$ when $\partial \Delta / \partial x<0$ and $\partial \Delta / \partial t \geq 0$ for all $t \varepsilon\left[0, t_{f}\right]$ and $\Delta_{f}<1$. We now assume that Condition $(R)$ holds for quasi-autonomous Lanchester-type equations and that $q(u)$ is convex in $u$ on $[0,+\infty)$ with $(\partial q / \partial u)_{f}<0$ and $u_{X}^{f}>1$. Then by Theorem $6 D_{c}$ is convex in $x_{0}$ and has a global minimum where $\partial D_{c} / \partial x_{0}=0$. This occurs, for example, for a classic "square-law" battle in which $\mathrm{dx} / \mathrm{dt}=-a y$ and $\mathrm{dy} / \mathrm{dt}$ -bx so that $q(u)=a /(b u)$. Moreover, a direct computation shows that $D_{c}=$ $y_{0}\left\{\left(u_{0}-1\right)-\left(u_{X}^{f}-1\right)\left[\left(u_{0}^{2}-a / b\right) /\left(\left(u_{X}^{f}\right)^{2}-a / b\right)\right]^{1 / 2}\right\}$. For fixed $y_{0}, D_{c}$ has a global minimum at $u_{0}^{*}=\left[(a / b)\left\{\left(u_{X}^{f}\right)^{2}-a / b\right\} /\left\{2 u_{X}^{f}-(I+a / b)\right\}\right]^{1 / 2}$. Numerical results are shown in Table IV. 
TABLE IV.

NUMERICAL RESULTS WHICH SHOW UNCONSTRAINED MINIMUM OF $D_{C}$ FOR "SQUARE-LAW" BATTLE WITH FIXED FORCE-RATIO BREAKPOINT.

\begin{tabular}{|c|c|c|c|c|c|}
\hline Battle & $\mathrm{u}_{0}$ & $\mathrm{x}_{0}-\mathrm{x}_{\mathrm{f}}$ & $\mathrm{y}_{0}-\mathrm{y}_{\mathrm{f}}$ & $\mathrm{D}_{\mathrm{c}}$ & $\mathrm{R}_{\mathrm{c}}$ \\
\hline 1 & 1.2 & 50.08 & 77.89 & -27.81 & 0.64 \\
2 & $\sqrt{2}$ & 36.01 & 66.67 & -30.655 & 0.54 \\
3 & $\mathrm{u}_{0}^{*}=1.44262$ & 34.66 & 65.34 & -30.683 & 0.53 \\
4 & 1.5 & 32.15 & 62.73 & -30.583 & 0.51 \\
5 & $\sqrt{3}$ & 24.13 & 52.86 & -28.73 & 0.46 \\
6 & 2 & 17.43 & 42.26 & -24.84 & 0.41 \\
7 & $\sqrt{5}$ & 12.79 & 33.33 & -20.54 & 0.38 \\
\hline
\end{tabular}

Other parameter values:

$$
\mathrm{b} / \mathrm{a}=1.0, \quad \mathrm{u}_{\mathrm{x}}^{\mathrm{f}}=\sqrt{10}, \quad \mathrm{y}_{0}=100.0
$$


6. Results When the Sign of $\partial(d x / d y) / \partial x$ is Always the Same Motivated by some Lanchester-type attrition processes that have appeared in the literature for which the sign of $\partial(\mathrm{dx} / \mathrm{dy}) / \partial \mathrm{x}$ is the same for all admissible values of $t, x$, and $y$, we state

Condition $(P)$ : the sign of $\partial(d x / d y) / \partial x$ is the same for all $t, x, y \geq 0$.

Condition (P) is satisfied, for example, for variable-coefficient Helmbold-type proces (for which $\Delta=\{a(t) / b(t)\}(x / y)^{1-d}$ ) or constant-coefficient aimed-fire battles with supporting fires not subject to attrition as studied by Taylor and Parry [21] (for whic $\Delta=(a+\beta u) /(\alpha+b u))$. The above results may then be somewhat more strongly stated.

THEOREM 7: Assume that Condition (P) holds and that the Lanchester-type equations (1) are quasi-autonomous. For a battle with a fixed force-level breakpoint to be won by $\mathrm{X}, \partial \mathrm{C} / \partial \mathrm{x}_{0}<0$ for $\mathrm{C}=$ $L_{X}, \quad R_{C}, \quad D_{C}$ if and only if $\partial(d x / d y) / \partial x<0$.

THEOREM 8: Assume that Conditions $(P)$ and $(R)$ hold and that the Lanchestertype equations (1) are quasi-autonomous. For a battle with a fixed force-ratio breakpoint to be won by $\mathrm{x}, \partial \mathrm{R}_{\mathrm{c}} / \partial \mathrm{x}_{0}<0$ if and only if $\partial \Delta / \partial u=\partial q / \partial u<0$. If $d x / d y=q(u)$ is a strictly convex (concave) function of $u$ on $[0,+\infty)$ and $\partial q / \partial u<0 \quad(>0)$, then $L_{X}$ and $R_{C}$ are strictly convex (concave) functions of $x_{0}$. The same is true for $D_{c}$ if additionally $u_{x}^{f}>1$.

Theorem 7 follows from (11), (18), (19), and Condition (P), since $\partial(\mathrm{dx} / \mathrm{dy}) / \partial t \equiv 0$. The statement about $\partial \mathrm{R}_{c} / \partial x_{0}$ in Theorem 8 follows from (33), (34), and (35), since $\mathrm{dN} / \mathrm{du}_{\mathrm{X}}^{\mathrm{f}}<0$ if and only if $\partial \Delta / \partial \mathrm{u}<0$. The latter inequality for $\mathrm{dN} / \mathrm{du}_{\mathrm{X}}^{\mathrm{f}}$ follows $\mathrm{frc}$ $\partial \mathrm{x}_{\mathrm{f}} / \partial \mathrm{x}_{0}>0$ and

$$
\mathrm{dN} / \mathrm{du} \mathrm{x}_{\mathrm{f}}^{\mathrm{f}}=\left\{-\mathrm{y}_{0}\left(\mathrm{R}_{\mathrm{c}}-\Delta_{\mathrm{f}}\right) /\left[\left(\mathrm{u}_{\mathrm{X}}^{\mathrm{f}}-\Delta_{\mathrm{f}}\right)^{2}\left(\mathrm{y}_{0}-\mathrm{y}_{\mathrm{f}}\right)\right]\right\} \partial \mathrm{x}_{\mathrm{f}} / \partial \mathrm{x}_{0},
$$

which holds by (40) with $\partial \Delta / \partial t \equiv 0$, since $R_{c}>\Delta_{f}$ if and only if $\partial \Delta / \partial u<0$. The proof of the last inequality follows along the lines of that for Lemma 1 . The proof the convexity statements in Theorem 8 follows along the lines of that for Theorem 6 . 


\section{The Concentration Decision in the face of an Enemy Victory}

Let us now briefly consider battles to be won by the enemy (i.e. Y). The above analysis must be entirely redone. In considering the initial-commitment decision, ve will assume that $x$ cannot turn the tide of battle (i.e. $0<x_{0}^{m i n} \leq x_{0} \leq x_{0}^{\max }=$ $\varepsilon_{0}^{\text {draw }}-\varepsilon$, where $\varepsilon>0$ ).

For a battle won by $Y$, we assume that $d x / d t<0$ for all $t \varepsilon\left[0, t_{f}\right]$ and parameterize the course of battle in terms of the $\mathrm{X}$ force level. Hence, we consider $y_{f}=y_{f}\left(x_{f} ; x_{0}, y_{0}\right), \quad x_{f}=x_{f}\left(x_{0}, y_{0}\right), \quad t=t\left(x ; x_{0}, y_{0}\right)$, and $y=y\left(x ; x_{0}, y_{0}\right)$. Writing $=y\left(x ; x_{0}, y_{0}\right)=y_{0}-\int_{x}^{x_{0}} d y / d x\left(t\left(x_{1} ; x_{0}, y_{0}\right), x_{1}, y\left(x_{1} ; x_{0}, y_{0}\right)\right) d x_{1}$, we obtain analogous to

$$
\begin{aligned}
\left(\partial y / \partial x_{0}\right)_{x, y_{0}}=\partial y / \partial x_{0}=-(d y / d x)_{0}- & \int_{x}^{x_{0}}\left\{\left(\partial t / \partial x_{0}\right) \cdot \partial(d y / d x) / \partial t\right. \\
& \left.+\left(\partial y / \partial x_{0}\right) \cdot \partial(d y / d x) / \partial y\right\} d x_{1} .
\end{aligned}
$$

When the equations ( 1 ) are quasi-autonomous, $\partial \mathrm{y}_{\mathrm{f}} / \partial \mathrm{x}_{0}=-\left(1 / \Delta_{0}\right) \exp \left\{\int_{\mathrm{x}_{\mathrm{f}}}^{\mathrm{x}_{0}}(\partial(\mathrm{dy} / \mathrm{dx}) / \partial \mathrm{y}) \mathrm{dx}\right\}$,

$$
\partial y_{f} / \partial x_{0}=-\left(1 / q_{0}\right) \exp \left\{\int_{x_{f}}^{x_{0}}(u / q)^{2}(1 / x)(\partial q / \partial u) d x\right\} .
$$

Caking account of the functional dependencies of $x_{f}$ and $y_{f}$, we see that the partial lerivatives (15) through (17) of the decision criteria now take the form

$$
\begin{gathered}
\partial \mathrm{L}_{\mathrm{X}} / \partial \mathrm{x}_{0}=1-\partial \mathrm{x}_{\mathrm{f}} / \partial \mathrm{x}_{0}, \\
\partial \mathrm{R}_{\mathrm{c}} / \partial \mathrm{x}_{0}=\left\{1+\mathrm{R}_{\mathrm{c}} \cdot \partial \mathrm{y}_{\mathrm{f}} / \partial \mathrm{x}_{0}-\left(1-\mathrm{R}_{\mathrm{c}} / \Delta_{\mathrm{f}}\right) \partial \mathrm{x}_{\mathrm{f}} / \partial \mathrm{x}_{0}\right\} /\left(\mathrm{y}_{0}-\mathrm{y}_{\mathrm{f}}\right), \\
\partial \mathrm{D}_{\mathrm{c}} / \partial \mathrm{x}_{0}=1-\left(1-1 / \Delta_{\mathrm{f}}\right) \partial \mathrm{x}_{\mathrm{f}} / \partial \mathrm{x}_{0}+\partial \mathrm{y}_{\mathrm{f}} / \partial \mathrm{x}_{0} .
\end{gathered}
$$

ior a battle with a fixed force-level breakpoint to be won by $Y$ (i.e. $x_{f}=x_{Y}^{f}$, shere $x_{Y}^{f}$ is a given quantity ${ }^{15}$ ), we have that $\partial x_{f} / \partial x_{0} \equiv 0$ so that the above become

$$
\partial \mathrm{L}_{\mathrm{X}} / \partial \mathrm{x}_{0}=1,
$$




$$
\begin{gathered}
\partial R_{c} / \partial x_{0}=\left\{1+R_{c} \cdot\left(\partial y_{f} / \partial x_{0}\right)\right\} /\left(y_{0}-y_{f}\right), \\
\partial D_{c} / \partial x_{0}=1+\partial y_{f} / \partial x_{0},
\end{gathered}
$$

From the above, we see that the initial-commitment decision for $\mathrm{X}$ is quite different (at least for a fixed force-level breakpoint) when $Y$ wins. If $X$ conside only his own losses $L_{X}$, then $x_{0}^{*}=x_{0}^{m i n}$. Considering (43) and (49), one can show that $\partial D_{c} / \partial x_{0}>0$ when Condition (R) holds for quasi-autonomous Lanchester-type equations, $\mathrm{q}_{0}=(\mathrm{dx} / \mathrm{dy})_{0} \geq 1$, and $\partial \mathrm{q} / \partial \mathrm{u}<0$ for all $\mathrm{t}\left[0, \mathrm{t}_{\mathrm{f}}\right]$, since $\mathrm{q}_{0} \geq 1$ and $\partial q / \partial u<0$ for all $t \in\left[0, t_{f}\right]$ imply that $\partial y_{f} / \partial x_{0}>-1$ by (43). Further examination of the initial-commitment decision in the face of an enemy victory is beyond the scope of our current investigation. By the above, however, it should be clear that results differ from those for the case in which $X$ wins.

\section{DISCUSSION}

In this paper we have shown that under the appropriate conditions Taylor and Parry's ${ }^{[21]}$ conjecture that the consequences from initially committing additional forc to battle may be determined from how the instantaneous casualty-exchange ratio varies with changes in the victor's force level and time is true. This determination does not require that the Lanchester-type combat equations be solved. As the example consi ered in Section 4 showed, temporal variations in the instantaneous casualty-exchange ratio for constant force levels (i.e. $\partial(d x / d y) / \partial t$ ) must be of a certain nature (see, example, Theorem 1) for our results to hold. This important qualification was not observed by Taylor and Parry ${ }^{[21]}$. Not only do these results apply to most cases of Lanchester-type combat between two homogeneous forces but also to such cases with superimposed effects of supporting weapons not subject to attrition as treated by Tayl and Parry. Furthermore, our new results may be extended to cases of continuous replac ments and/or withdrawals. 16

Let us now apply our general results to the constant-coefficient model, $\mathrm{dx} / \mathrm{dt}$ $-a y-\beta x, \quad d y / d t=-b x-\alpha y$, considered by Bach et al. [1] and Taylor and Parry ${ }^{[21]}$. By Theorems 7 and 8 , when the overall casualty-exchange ratio $R_{c}$ is the decision criter 
the victor $X$ should initially commit as many forces to battle as possible (1.e. $x_{0}^{*}=x_{0}^{\max }$ ) if and only if $a b>\alpha \beta$, regardless of which of the two battle-termination nodels is used. For fixed force-level breakpoint battles, the initial-commitment decision does not depend on which of the three criteria is used. Moreover, as first shown by Bach et al. ${ }^{[1]}$, there are diminishing marginal returns from inftially committing additional forces to battle when this is the optimal action. Our new results provide an explanation for these diminishing returns: the instantaneous casualty-exchange ratio $\mathrm{dx} / \mathrm{dy}=\mathrm{q}(\mathrm{u})=(\mathrm{a}+\mathrm{Bu}) /(\alpha+b u)$ is a convex function of $u$ on $[0,+\infty)$ when $a b>\alpha \beta$ (see Theorem 8).

If the combat between primary systems follows a Helmbold-type ${ }^{[8]}$ attrition process (see Section 4 above and Taylor ${ }^{[17]}$ ) in the above example, then the combat dynamics are given by $\mathrm{dx} / \mathrm{dt}=-\mathrm{a} \cdot(\mathrm{x} / \mathrm{y})^{c} \mathrm{y}-\beta \mathrm{x}$ and $\mathrm{dy} / \mathrm{dt}=-\mathrm{b} \cdot(\mathrm{y} / \mathrm{x})^{c} \mathrm{x}-\alpha \mathrm{y}$. In this case we nave $d x / d y=q(u)=u\left(a u^{-d / 2}+\beta\right) /\left(\alpha+b u^{d / 2}\right)$ and $\partial q / \partial u=\{\alpha \beta-(d-1) a b+$ $\left.(1-d / 2)\left(\alpha a u^{-d / 2}+\beta b u^{d / 2}\right)\right\} /\left(\alpha+b u^{d / 2}\right)^{2}$, where $d=2(1-c)$. Hence, the victor $x$ should hever initially commit as many forces to battle as possible when $d \leq 1$. The same con: Iusion holds for $a l l d \leq 2$ when $\alpha \beta>a b$. For $1<d<2$ and $\alpha \beta<a b$, $\partial q / \partial u$ may hange sign over the course of battle, and then it is not possible to invoke our theorems. This last example brings to mind an important aspect of our results: our esults (in particular, Theorems 1, 3, 4, and 5) provide sufficient conditions for the ptimal course of action to be to initially commit as many forces as possible. Since re are dealing with sufficient conditions, it may still be optimal to initially commit s much as possible even when such conditions are not satisfied.

All the above results show that with supporting fires present one should not 1ways commit as many primary forces as possible in aimed-fire battles, but one must rade-off vulnerability to supporting fires against the increased fire effectiveness rom massing primary systems. Military interpretations for various quantities such as b are to be found in Taylor and Parry ${ }^{[21]}$. Thus, this work shows that in our nuclear ge with supporting weapons of great effectiveness, merely commiting large numbers of orces to battle may not always be the "best" thing to do. 
Our work here shows the importance of battle-termination conditions for combat evaluations. We saw that different optimal initial-commitment actions were possible in fixed force-level breakpoint battles and fixed force-ratio breakpoint battles. In particular, the loss ratio and the loss difference may yield different initial-commitment decisions for a fixed force-ratio breakpoint battle, although they yield the same decision for a fixed force-level breakpoint battle. Similar results on the sensitivity of optimal time-sequential fire-distribution policies to battle-termination conditions have been pointed out by the author ${ }^{[14,15]}$. Consequently, we feel that more scientific work is required on modelling conflict termination ${ }^{17}$ (see Taylor ${ }^{[14]}$ for references). As is always the case, however, the insights gained into combat dynamics from such Lanchester-type models are no more valid than the models themselves.

\section{NOTES}

1. It was the author's good fortune to be awarded (jointly with S. Parry) the 1975 MAS Prize by the Milftary Applications Section of ORSA for the three papers Taylor and Parry [21], Taylor [17], and the paper at hand. The MAS Prize is awarded annually for the best paper on military operations research that is submitted in response to a solicitation.

2. The instantaneous (or differential) casualty-exchange ratio is given by $\mathrm{dx} / \mathrm{dy}=$ $F(t, x, y) / G(t, x, y)$ for the mode1 (1) with no replacements and withdrawals. We may think of it as the ratio of each side's casualties that occur in a short interval of time $d t$.

3. One of the half dozen or so principles of war (see references 5, 12, and 22) is the principle of concentration (or mass), which would have a commander concentrate as many men and means for battle as possible at the decisive point. The exact number of principles of war varies from author to author.

4. See references 16, 17, 19, and 21 for further information about such models.

5. Extension to cases with replacements and/or withdrawals is outlined in Note 16 belo 
6. As Borch ${ }^{[4]}$ has emphasized, it will not make much sense to study decisions under uncertainty unless we know how to make decisions under full certainty.

7. As pointed out in reference 21 , the entire topic of modelling battle termination is a problem area in contemporary defense planning studies, and there is far from universal agreement on this topic. For further references see Taylor [14].

8. For our idealized deterministic model, $\varepsilon>0$ may be taken to be arbitrarily small. In the real world with its various uncertainties, a larger value would be desirable as a "hedge" against uncertainty (see reference 21 and p. 322 of reference 1).

9. Quasi-autonomous Lanchester-type equations of modern warfare have, for example, been considered by Bonder and Farrell ${ }^{[2]}$ and Taylor ${ }^{[13]}$ (see also Note 4 of reference 19). 10. Piecewise-constant attrition-rate coefficients may be reagrded as a limiting case of twice continuously differentiable coefficients. The former are certainly much more convenient to use for this counterexample.

11. The first equation of Table I may be obtained in the following manner. First, we observe that the substitution $p=x^{1-c}$ and $q=y^{1-c}$ transforms the nonlinear equations (22) into the following linear system

$$
\mathrm{dp} / \mathrm{dt}=-(1-\mathrm{c}) \mathrm{a}(\mathrm{t}) \mathrm{q}, \quad \mathrm{dq} / \mathrm{dt}=-(1-\mathrm{c}) \mathrm{b}(\mathrm{t}) \mathrm{p} \text {. }
$$

[This important transformation was apparently first noted in Taylor [18] for a more general model.] Next, we consider the case in which the above model has constant attrition-rate coefficients. When $\mathrm{X}$ wins, the time for $\mathrm{Y}$ to reach his breakpoint, ${ }_{f}$, then follows from well-known constant-coefficient results (see, for example, equation (8) of Taylor and Comstock ${ }^{[20]}$ ).

12. See, for instance, Farrell and Freedman ${ }^{[7]}$ for an example of the use of such battletermination conditions in contemporary defense analysis.

13. Equation (25) is developed in the following manner. From (3) and the definition of $u_{x}^{f}$, we have 


$$
x_{f}\left(y_{f}\left(x_{0}, y_{0}\right) ; x_{0}, y_{0}\right)=u_{x}^{f} \cdot y_{f}\left(x_{0}, y_{0}\right)
$$

Since, $u_{x}^{f}$ is a given constant, differentiation with respect to $x_{0}$ yields

$$
\left(\partial x_{f} / \partial y_{f}\right)_{x_{0}, y_{0}} \cdot\left(\partial y_{f} / \partial x_{0}\right)_{y_{0}}+\left(\partial x_{f} / \partial x_{0}\right)_{y_{0}, y_{f}}=u_{x}^{f} \cdot\left(\partial y_{f} / \partial x_{0}\right)_{y_{0}},
$$

which yields the desired result via (13).

14. Since $x_{0}$ and $y_{0}$ are fixed in this development, we have that $x_{f}$ is a function of only $y_{f}$ so that

$$
R_{c}=\left(x_{0}-x_{f}\left(y_{f}\right)\right) /\left(y_{0}-y_{f}\right) \text {. }
$$

For a fixed force-ratio breakpoint battle, we may consider that $y_{f}$ is a function of $u_{X}^{f}$. Differentiation of the above expression for $R_{c}$ with respect to $u_{X}^{f}$ yields the desired result (38) by use of the identity $d y_{f} / d u_{x}^{f}=-y_{f} /\left(u_{x}^{f}-\Delta_{f}\right)$, which follows from (26).

15. Thus, one assumes that the $X$ force is effective only for $x>x_{Y}^{f}$. In other words one is assuming that by the time the $X$ force level reaches $x_{Y}^{f}$, the unit has suffered so many casualties (and also lost key personnel) that it ceases to be an effective fighting force. One normally writes that $x_{Y}^{f}=f_{B P}^{X} x_{0}$, where $f_{B P}^{X}$ denotes a given fraction of $\mathrm{X}^{\prime}$ 's initial strength (for further details, see Section 2 of Taylor and Comstock ${ }^{[20]}$ ). The breakpoint fraction $\mathrm{f}_{\mathrm{BP}}^{\mathrm{X}}$ is usually assumed to depend on the tactical posture of the unit, unit size, its morale and training, etc. A typical value (frequently used in defense analyses) for $\mathrm{f}_{\mathrm{BP}}^{\mathrm{X}}$ is 0.7 for a company-sized unit in the attack.

16. The extension of these results to cases of continuous replacements and/or withdrawals becomes quite complex, however. We will now briefly examine such an extension. Let $\mathrm{n}_{\mathrm{X}}(\mathrm{t})$ denote the net rate of influx of replacements for $\mathrm{X}$, and similarly for $\mathrm{n}_{Y}(t)$. Then, denoting $\mathrm{X}^{\prime} \mathrm{s}$ casualties as $\mathrm{x}_{c}$, we have

$$
x_{c}=x_{0}-x_{f}+N_{X}
$$


where $\mathrm{N}_{\mathrm{X}}=\int_{0}^{t} \mathrm{n}_{\mathrm{X}}(\mathrm{s}) \mathrm{ds}$, and similarly for $\mathrm{y}_{\mathrm{c}}$. It follows that
\[ \partial \mathrm{x}_{\mathrm{c}} / \partial \mathrm{x}_{0}=1-\partial \mathrm{x}_{\mathrm{f}} / \partial \mathrm{x}_{0}+\mathrm{n}_{\mathrm{X}}\left(t_{\mathrm{f}}\right)\left\{(\mathrm{dt} / \mathrm{dy})_{\mathrm{f}} \cdot \partial \mathrm{y}_{\mathrm{f}} / \partial \mathrm{x}_{0}+\partial t_{\mathrm{f}} / \partial \mathrm{x}_{0}\right\} \text {, } \]

and

$$
\partial y_{c} / \partial x_{0}=-\partial y_{f} / \partial x_{0}+n_{Y}\left(t_{f}\right)\left\{(d t / d y)_{f} \cdot \partial y_{f} / \partial x_{0}+\partial t_{f} / \partial x_{0}\right\}
$$

where $(d t / d y)_{f}$ denotes the final value for $1 /(d y / d t)$. Recalling that $L_{X}=x_{C}$, $R_{c}=x_{c} / y_{c}$, and $D_{c}=x_{c}-y_{c}$, we have for a fixed force-level breakpoint battle (in which $y_{f}=$ constant)

$$
\begin{gathered}
\partial \mathrm{L}_{\mathrm{X}} / \partial \mathrm{x}_{0}=1-\partial \mathrm{x}_{\mathrm{f}} / \partial \mathrm{x}_{0}+\mathrm{n}_{\mathrm{X}}\left(\mathrm{t}_{\mathrm{f}}\right) \cdot \partial \mathrm{t}_{\mathrm{f}} / \partial \mathrm{x}_{0}, \\
\partial \mathrm{D}_{\mathrm{C}} / \partial \mathrm{x}_{0}=1-\partial \mathrm{x}_{\mathrm{f}} / \partial \mathrm{x}_{0}+\left\{\mathrm{n}_{\mathrm{X}}\left(\mathrm{t}_{\mathrm{f}}\right)-\mathrm{n}_{\mathrm{Y}}\left(\mathrm{t}_{\mathrm{f}}\right)\right\} \partial \mathrm{t}_{\mathrm{f}} / \partial \mathrm{x}_{0},
\end{gathered}
$$

and

$$
\partial R_{c} / \partial x_{0}=\left\{1-\partial x_{f} / \partial x_{0}+\left[n_{X}\left(t_{f}\right)-R_{C} \cdot n_{Y}\left(t_{f}\right)\right] \partial t_{f} / \partial x_{0}\right\} /\left(y_{f}-y_{0}\right)
$$

The above partial derivatives should be compared with the analogous ones (15) through (17) for the case of no replacements and withdrawals. Further examination of such an extension is beyond the scope of our current investigation.

17. Here we mean that more effort should be spent on developing scientifically valid models of conflict termination because of the sensitivity of analysis results to such mode1s.

\section{ACKNOWLEDGMENTS}

This research was supported by the office of Naval Research (partially through the Foundation Research Program at the Naval Postgraduate School and partially through direct funding). The author would like to thank the two referees and an associate editor for their generous help in improving this paper. 


\section{REFERENCES}

1. R. Bach, L. Dolansky, and H. Stubbs, "Some Recent Contributions to the Lanchester Theory of Combat," Opns. Res. 10, 314-326 (1962).

2. S. Bonder and R. Farrell (Editors), "Development of Models for Defense Systems Planning," Report No. SRL 2147 TR 70-2 (U), Systems Research Laboratory, The University of Michigan, Ann Arbor, Michigan, Sept. 1970.

3. S. Bonder and J. Honig, "An Analytic Model of Ground Combat: Design and Application, Proceedings U. S. Army Operations Research Symposium 10, 319-394 (1971).

4. K. Borch, The Economics of Uncertainty, Princeton University Press, Princeton, New Jersey, 1968.

5. Lt. Col. A. H. Burne, The Art of War on Land, The Military Service Publishing Co., Harrisburg, Pennsylvania, 1947.

6. L. Dolansky, "Present State of the Lanchester Theory of Combat," Opns. Res. 12, 344-358 (1964).

7. R. Farrell and R. Freedman, "Investigations of the Variation of Combat Model Predictions with Terrain Line of Sight," Report No. AMSAA-1, FR75-1, Vector Research, Inc., Ann Arbor, Michigan, January 1975.

8. R. Helmbold, "A Modification of Lanchester's Equations," Opns. Res. 13, 857-859 (1965).

9. F. W. Lanchester, "Aircraft in Warfare: The Dawn of the Fourth Arm-Vol. V., The Principle of Concentration," Engineering 98, 422-423 (1914) (reprinted on pp. 21382148 of The World of Mathematics, Vol. IV, J. Newman (Editor), Simon and Schuster, New York, 1956).

10. I. Petrovski, Ordinary Differential Equations, Prentice-Hall, Englewood Cliffs, New Jersey, 1966 (reprinted by Dover Publications, Inc., New York, 1973).

11. G. Pugh and J. Mayberry, "Theory of Measures of Effectiveness for General-Purpose Military Forces: Part I. A Zero-Sum Payoff Appropriate for Evaluating Combat Strategies," Opns. Res. 21, 867-885 (1973).

12. V. Savkin, The Basic Principles of Operational Art and Tactics, Moscow, 1972 (translated and published by the U. S. Government Printing Office, Washington, D.C.)

13. J. Taylor, "A Note on the Solution to Lanchester-Type Equations with Variable Coefficients," Opns. Res. 19, 709-712 (1971).

14. J. Taylor, "Survey on the Optimal Control of Lanchester-Type Attrition Processes," presented at the Symposium on the State-of-the-Art of Mathematics in Combat Models, June 1973 (also Tech. Report NPS55Tw74031, Naval Postgraduate School, Monterey, California, March 1974).

15. J. Taylor, "Lanchester-Type Models of Warfare and Optimal Control," Naval Res. Log. Quart. 21, 79-106 (1974).

16. J. Taylor, "Solving Lanchester-Type Equations for 'Modern Warfare' with Variable Coefficients," Opns. Res. 22, 756-770 (1974). 
17. J. Taylor, "On the Relationship Between the Force Ratio and the Instantaneous Casualty-Exchange Ratio for Some Lanchester-Type Models of Warfare," Naval Res. Log. Quart. 23, 345-352 (1976).

18. J. Taylor, "Some Simple Victory-Prediction Conditions for Lanchester-Type Combat Between Two Homogeneous Forces with Supporting Fires," submitted to Opns. Res.

19. J. Taylor and G. Brown, "Canonical Methods in the Solution of Variable-Coefficient Lanchester-Type Equations of Modern Warfare," Opns. Res. 24, 44-69 (1976).

20. J. Taylor and C. Comstock, "Force-Annihilation Conditions for Variable-Coefficient Lanchester-Type Equations of Modern Warfare," Naval Res. Log. Quart. 24, to appear (No. 2, 1977).

21. J. Taylor and S. Parry, "Force-Ratio Considerations for Some Lanchester-Type Models of Warfare," Opns. Res. 23, 522-533 (1975).

22. U. S. Military Academy, Notes for the Course in the History of the Military Art, West Point, New York, 1964.

23. H. Weiss, "Requirements for a Theory of Combat," Memorandum Report No. 667 , Ballistic Research Laboratories, Aberdeen Proving Ground, Maryland, April 1953.

24. H. Weiss, "Lanchester-Type Models of Warfare," pp. 82-98 in Proc. First International Conference on Operational Research, John Wiley, New York, 1957. 
Advanced Research Projects Agency

Department of Defense

Washington, D. C. 20301

(Technical Library)

Chairman, Joint Chiefs of Staff

Studies Analysis and Gaming Agency

Washington, D. C. 20350

Defense Documentation Center

Cameron Station

Alexandria, VA 22314

Chief of Naval Operations

Department of the Navy

Washington, D. C. 20350

Headquarters, Marine Corps (AX)

Washington, D. C. 20380

Office of Naval Research

Department of the Navy

Arlington, VA 22217

(Code 431)

(Code 432)

(Mr. Alvin F. Andrus, Code 230)

(Dr. Toke Jayachandran, Code 431)

(Mr. James F. Smith, Code 431)

Naval War College

Newport, Rhode Island 02840

(Technical Library)

Nava1 Ordnance Laboratory

Silver Spring, MD 20910

(Technical Library)

Nava1 Research Laboratory

Washington, D. C. 20390

(Code 2029)

Director, Army Research

Office of the Chief for Research and Development

Department of the Army

Washington, D. C. 20310

Dr. Wilbur B. Payne, Director

U. S. Army TRADOC Systems Analysis Activity

White Sands Missile Range, NM 88002 
Mr. H. K. Weiss

P. O. Box 2668

Palos Verdes Peninsula

Palos Verdes, CA 90274

Library (Code 55)

Department of Operations Research

Naval Postgraduate School

Monterey, CA 93940

Library (Code 0212)

Naval Postgraduate School

Monterey, CA 93940

Dean of Research

Code 023

Naval Postgraduate School

Monterey, CA 93940

Professor James G. Taylor, Code 55Tw

Professor Samuel H. Parry, Code 55Py

Professor Michael G. Sovereign, Code 55Zo

Professor Gerald G. Brown, Code 55Bw

Department of Operations Research

Naval Postgraduate School

Monterey, CA 93940

CDR Karl H. Eulenstein

Commander-in-Chief Pacific

Code J021, Box 13

FPO San Francisco 96610 

DUDLEY KNOX LIBRARY - RESEARCH REPORTS

56853010710262

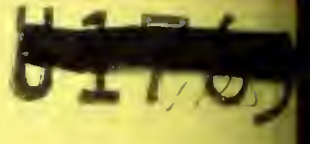

